\title{
13 Glossy Glossary
}

In conclusion, the mosaic of the chapters on emotional and physical experiences of wellbeing and escapism, melancholy and destruction (Chapters 2-5), depicted some contexts of language in liminality - beach, transgression, time travel and transformation. The subsequent parts of the composition dealt with linguistic realities of disrupted landscapes, communities and interactions (Chapters 6-8), and with questions of language as a commodified, hostile, estranged and misleading thing not really shared any longer among people in mass tourism settings (Chapters 9-13).

It is remarkable how many aspects of humanity and conviviality get lost in the process of what we have described: a wealth of hospitableness and encountering which would have been an important part of social and cultural life in the various communities in question. While such observations are largely ignored in many linguistic publications on the languages of the tropics, Global South and the postcolony alike (as if this would make a difference), they are crucial in reflecting the situations in which speakers are often forced to interact.

The state of emergency that is everywhere in these chapters and settings asks for even more disruption, we think, in the ways in which we write our conclusive remarks: a glossary, which is nothing more than a few more colourful mosaic stones thrown onto the table.

\section{Scratch card}

On a flight with a low budget airline, scratch cards were sold for the price of 2 Euros apiece. The steward announced the sale of the cards over the microphone and explained that the profit would be used to do good. The airline, which is constantly in the news regarding the low income and bad working conditions of its staff, engages in charity tourism. What is behind it? The scratch card names five humanitarian aid organizations that the airline supports. A small picture shows the handover of a cheque on which one can hardly distinguish the sum that was donated to one of the organizations. The very small picture shows the very small letters saying 'ten thousand Euros'. It is not a large sum, we assume, that is gained through the manipulation of the emotions of travellers, who on their journey are pressured to invest pocket money in charitable trusts. 
Similar strategies are used elsewhere, on diverse flights and with diverse interests: data-extraction, bonding, rehabilitating.

Taxi

The taxi in Cairo is a haven, even a home. It features fragrance, soft cushions and even a spiritual object - the rosary hanging from the rear mirror. All objects help to build common ground, the basis of communication between the driver and the client. In the glove box there is a guest book, a photo album and a collection of letters of recommendation.

\section{Pyramid}

As the epitome of the tourist attraction, the pyramid is everywhere. In the ideal case, it serves as a screen for sound and light shows.

\section{Bingo}

In the holiday resort, bingo enjoys a somewhat ambiguous reputation. On the one hand, it is a game that is associated with the monotony of allinclusive consumerism, and on the other hand, it enjoys a kind of cult status, given the splendid things that one can win. For example, a black and golden glitter notebook for future expeditions, or a purple cocktail shaker for blue hours. For linguists, bingo is not only a treasure trove of paraphrases and metaphors, but also a way to obtain better things and lives.

\section{White paint}

Wood painted white indicates organic food, fish and salad. Aquamarine accessories indicate a breeze on a hot day.

\section{Delay}

The delay of a plane or train or guide is terrible. But it is necessary: 'That what travel means is not just misfortune but seeking misfortune. In some sense, wanting it. And it is of such crucial importance to us that we must call it religious', as Frederick Ruf (2007: 4) writes in Bewildered Travel.

\section{Forgetting}

One always forgets vocabulary once learned and then this is the moment when one thinks that one knows nothing. Augé (2001), however, states that forgetting is elemental for society as well as for the individual. One needs to know how to forget in order to be able to appreciate and seize the present moment.

\section{Exotic African liquid}

Cream liqueur is difficult to advertise, and therefore it is given remarkable names. Amarula, for example, and Kablua. A drink, but the images and 
songs in which it features seem to have a stronger impact than the sweet alcoholic beverage itself. The bottles evoke emotions and imply a desire for something wild, free. Amarula is safari. As a song, it is sex. The name is pronounced as rhythm. Not word, but rhythm. And it bears in itself exoticism and happiness. Like the medicament Umckaloabo, which cures nausea or flu, the effect of this liquid is prepared by the rhythmic chorus through which it is advertised. In this way, these concoctions resonate imagined 'ageold' knowledge of 'primordial' societies to heal and make things beautiful.

\section{Culinary entitlement}

Our host says: 'The more money is involved, the more trouble you get.' In the upscale resorts where upscale tourists stay, the promised free sundowner that someone might have forgotten to serve (a waiter, a waitress) is a legal affair. The buffet that offers a selection of 10 different starters and 11 mains is a site of gluttony where clients find it hard to miss out on even a single item. What has been paid for has to be made available, has to be ingested. The notion of entitlement in tourism wherever its protagonists have the verbal and material power to claim whatever they think is theirs creates precisely the environmental destruction and consumerist outfall they so despise. Entitlement to water results in a poisonous gift of small plastic bottles, which will not decompose within the next 800 years.

\section{Collectibles}

Plane-shaped salt dispenser. Foldable hairbrush. Foldable toothbrush. Sleeping mask. Cake of frangipani soap. All-inclusive ribbon. Ballpen and notepad. Beach towel. Stickers. Pebbles, sand, seashells. Phone numbers. Memories.

\section{Barter trade}

Things for feelings. Prior to the trip to the resort in Africa, things that are no longer wanted are put into the suitcase: clothes, pens, shoes, a watch. At the end of the holiday all this will have been given away, donated, gifted. After check-out, a T-shirt and a pair of flip-flops remain in the room. Gestures of gratefulness and smiles are the reward. Letting go of the things that make life tedious is grounding. Junk export works where Othering takes place, where those who receive leftovers are considered sufficiently different from the now cleansed giver.

\section{Daily special}

Chicken schnitzel/Vichy carrots/potato wedges with cajun spice Dijon mustard sauce 900 .

Mama mboga - pomodoro, mozzarella, spinach, carrot, baby marrow, sweet pepper 1200 .

Green curry w/ prawns OR Green curry w/ vegetables 1500/1300.

Paradise cooler 650 . 


\section{No diving}

Written beside each pool. It is supposed to warn swimmers that the pool is not deep enough, that they might get hurt. It might also refer to in-depth political enquiry, like into the Alliance Safari, once owned by the former candidate for presidency, Matiba, who was tortured and is no longer alive. The bar keeper suddenly becomes silent. You are not allowed to touch the ground. The foundations of the resort, hotel, airport, sightseeing platform are obscured by plaster, decoration and poolscapes. Poolscapes are very bright, turquoise, always turquoise.

\section{Nomad}

Clients are now nomads. At the nomadic places they patronize, a sustainable lifestyle is possible. Eco projects, women's cooperatives, something to do with animals and the local community. A privileged social class responsible for extraction and ruination cannot bear to look at the outfall produced by their desire and consumption. Nomads are imagined as people who leave no trace but simply move through the savannah until they are out of sight.

\section{Premium}

Upgraded tourists travel in a way no way different from those on the average seats: they feel the same turbulences. What differs is the larger seat, the free champagne, the cotton napkin, the priority handling of their baggage. When such things don't work out as promised, the money invested in such class performance has been spent in vain. Waiting among the other passengers for luggage is downgrading. It is interesting that the verb upgrade is used frequently in global tourism, while opposite, downgrade, doesn't even seem to exist.

\section{Return journey}

By the time it is time to travel back home, we have just finished writing this book. All chapters are stored safely in their folders, and we share a delightful lunch to celebrate. We put our suitcases in the taxi and head towards Mombasa airport. Rain falls. The bypass that serves as the only access road, while the highway, intended to connect port, railway and airport, remains under construction, has turned into a muddy slope. Moving amidst the sliding trucks, we are still on time. Other tourists in other cars get stuck, as do the airline crew. The flight is delayed until the exhausted air hostesses also reach the airport. Going on for years now, the neglect and exploitation of entire regions results in ruination to the extent that finally even this breaks down: tourism on those beaches, the Kenyan beaches where part of our research took place, is on the decline, as everybody there said. 
